\title{
Achieving the Millennium Development Goals
}

\author{
The Role of Infrastructure
}

\author{
Danny Leipziger, Marianne Fay, Quentin Wodon and Tito Yepes ${ }^{1}$
}

\begin{abstract}
$\underline{\text { Abstract }}$
This paper provides an empirical analysis of the determinants of three child health outcomes related to the Millennium Development Goals: the infant mortality rate, the child mortality rate, and the prevalence of malnutrition. Using data from Demographic and Health Surveys, the paper goes beyond traditional cross-country regressions by exploiting the variability in outcomes and explanatory variables observed within countries between asset quintiles. The paper shows the relationships existing between the prevalence of diseases (diarrhea and malnutrition) and mortality. The findings suggest that apart from traditional variables (income, assets, education and direct health interventions), better access to basic infrastructure services has an important role to play in improving child health outcomes. The analysis of interaction effects between interventions also suggests the importance of combining interventions in order to meet the Millenium Development Goals.
\end{abstract}

JEL categories: I12, O10, H42

Keywords: Millennium Development Goals, Infant mortality, Malnutrition, Infrastructure

World Bank Policy Research Working Paper 3163, November 2003

The Policy Research Working Paper Series disseminates the findings of work in progress to encourage the exchange of ideas about development issues. An objective of the series is to get the findings out quickly, even if the presentations are less than fully polished. The papers carry the names of the authors and should be cited accordingly. The findings, interpretations, and conclusions expressed in this paper are entirely those of the authors. They do not necessarily represent the view of the World Bank, its Executive Directors, or the countries they represent. Policy Research Working Papers are available online at http://econ.worldbank.org.

\section{Corresponding author:}

Marianne Fay

World Bank, 1818 H Street

Washington, DC 20433

Email: mfay@worldbank.org

\footnotetext{
${ }^{1}$ This paper was prepared in the Finance, Private Sector and Infrastructure Department of the Latin America and the Caribbean Vice Presidency at the World Bank as part of a research program on MDGs and Infrastructure.
} 


\section{Introduction}

In September 2000, the 189 member states of the United Nations unanimously adopted the Millennium Declaration. The Declaration outlines key development challenges, proposes a response to these challenges and defines a series of targets and progress measures. There are eight broad goals (the so-called Millennium Development Goals, or MDGs hereafter), with 15 targets that are to be monitored through a set of 48 indicators. $^{2}$ The aim is to achieve these targets by 2015 .

The setting of human development goals is not new to the development literature. Many in the early 1980s viewed the development challenge through the optic of basic human needs, a series of necessities that the donor community was to commit itself to provide the poor ${ }^{3}$. Today, the development challenge is no less daunting than it was two decades ago. In the intervening years, global growth has surged, a few primarily Asian countries have broken through the poverty barrier, and some significant progress in trade opening has occurred. These developments notwithstanding, and despite some gains in reducing the demographic explosion, the number of poor people has increased dramatically. Hence the attraction to the MDGs as a way to re-ignite development efforts.

To many, the goals encapsulate some of the key development challenges facing governments and international donors. To others, goals 2 through 8 seem superfluous as long as the first - eradication of extreme poverty and hunger- is tackled. Since improvements in most indicators of development are highly correlated with gains in per capita income, they argue, why bother with specific aims in health and education?

The answer to this first question is that economic growth should help, but will not be sufficient to achieve the MDGs. ${ }^{4}$ Performance in health, education and gender equity are clearly influenced by income levels. Table 1 shows, for example, that maternal

\footnotetext{
${ }^{2}$ The eight goals are to: eradicate extreme poverty and hunger, achieve universal primary education, promote gender equality and empower women, reduce child mortality, improve maternal health, combat HIV/AIDS, malaria and other diseases, ensure environmental sustainability, and develop a global partnership for development. For more information, see http://sima.worldbank.org/mdg/. For a review of progress on the International Development Goals see www.paris21.org/betterworld.

${ }^{3}$ See for example Streeten (1977), Hicks (1979), Hicks and Streeten (1978), and Leipziger (1981).

${ }^{4}$ Simulations suggest that many countries may not in fact achieve the targets put forward in the MDGs unless they substantially change their policies. For Latin America, see for example Hicks and Wodon (2002).
} 
mortality rates in upper middle income countries are a fraction $\left(1 / 7^{\text {th }}\right)$ of what they are in low income countries. The same observation can be made for the prevalence of malnutrition among children and child mortality rates, both of which drop as income rises: rates in middle income countries are half those of low income countries and more than twice those of high income countries. Similarly school enrollment rates and ratios of female to male literacy rates are much lower in low income countries.

However, within income categories, large differences in outcomes suggest that income is not the sole determinant of the indicators used in the MDGs. Other factors and policies could be effective in improving well-being, For example, as suggested by Jayasuriya and Wodon (2003), GDP per capita is only one of several key inputs entering the "production function" for the MDGs, and beyond these inputs, there are also issues regarding the efficiency with which countries use their available resources to achieve these goals, and the key determinants of this efficiency. This point is clearly made by Figure 1, which illustrate the wide range of outcomes in child mortality and nutritional status of children within income categories in developing countries. Thus, some of the poorest countries outperform upper middle income countries in infant mortality rates and in nutritional status of children.

Beyond the risk of emphasizing income growth to the detriment of other policy interventions, a second question is whether in the urgency to meet individual targets, the development community is at risk of losing sight of the multi-sectoral nature of interventions and development outcomes such as the MDGs. Again, the emphasis on linkages among sectors is not new to the development literature. ${ }^{5}$ But we argue here that the MDGs will be useful tools only if they are not seen as narrow objectives with unidimensional interventions. To be concrete, it would be counter-productive if the goal of universal primary education were to be equated with higher spending on primary education. Primary education improvement in a particular country may well depend on better transportation networks in rural areas, in the same way that lower infant mortality

\footnotetext{
${ }^{5}$ A generation of development economists labored over general equilibrium models of development trying to clearly specify the interactions between policy interventions and development outcomes. Recall the path breaking work of Adelman and Robinson (1975), Adelman (1975) and the consolidation of this line of inquiry by Dervis, De Melo and Robinson (1982).
} 
may depend crucially on clean water, or gender equality in school enrollment may hinge on access to piped water (facilitating girl child school attendance.)

The role of multi-sectoral linkages in the achievement of MDG-like goals has long been recognized (see, for example, Lewis, 1981; De Melo, 1981; and Crosswell, 1981), but it deserves renewed emphasis since they are key to reaching the MDGs, and doing so at potentially lower cost. There are clear gains from multi-sectoral interventions such as maternal and child health interventions (health, nutrition and family planning), as well as from water, sanitation and shelter and other bundled interventions. The effectiveness of multiple interventions in infrastructure, for example, can be shown to yield economies of delivery (Chong and Hentschel, 2003.) Yet inter-sectoral connections are often under-played when designing the average health, education or infrastructure project. For this reason, a renewed emphasis on multi-sectoral factors that affect MDGs is useful.

A key argument presented in this paper is that some of the biggest improvements are likely to come from combining interventions. For example, it is well known that the health impact of improved water and sanitation is much greater when it is accompanied by information on hygiene practices - this is the motivation of the Public-Private Partnership for Handwashing with Soap, a global initiative to promote handwashing with soap to reduce diarrhea. ${ }^{6}$ Similarly, Jalan and Ravallion (2001) argue for the need to combine infrastructure interventions with effective public action to promote health knowledge: their research on India shows that diarrhea is much less prevalent and severe among young children in households with piped water, but that this gain largely bypasses children in poor households, particularly when the mother is poorly educated.

Figure 2 provides a simple heuristic illustration of the importance of combining interventions. Using the results from a simple regression, it shows that after correcting for income, countries that had high health care and infrastructure access scores had infant mortality rates on average 25.4 points lower that those who fared badly on both count. Faring well on only health or infrastructure brought about 4.1 and 13.1 point

\footnotetext{
${ }^{6}$ A recent review in The Lancet Infectious Diseases Journal (http://infection.thelancet.com/) suggests that a surprising $42-47 \%$ of all diarrhea could be prevented if people washed their hands with soap, thereby saving close to one million lives. There is growing evidence that hand washing also works to prevent acute respiratory tract infections, which are the biggest infectious killers in the world today. For more information on the Partnership, see: http://www.globalhandwashing.org/
} 
improvements, respectively. More striking is the fact that the impact of improved health interventions on infant mortality appears much greater if infrastructure is already relatively high (12.3 points vs 4.1). Similarly, the impact of improved infrastructure is almost twice as high if health interventions are already prevalent.

The regression used to derive Figure 2 is admittedly simplistic, but it does suggest that gains could be achieved from multi-sectoral interventions. The objective of this paper is to explore this conjecture more systematically. In section 2 , we provide a brief review of the literature on the determinants of children's health outcomes - a key component of the MDGs, and we discuss what we know of the role of infrastructure in that context. Section 3 outlines a simple reduced form model for estimating the determinants of child health outcomes using cross-country quintile level data. We then present our empirical results for the estimation of this model in Section 4 and conclude in Section 5.

\section{Determinants of Child Health: Brief Literature Review}

This paper provides an empirical analysis of the determinants of child health in order to make the case for the importance of combining interventions, including access to basic infrastructure services, in order to meet the MDGs. Why focus on child health, rather than poverty reduction or gender equality? Part of the decision is opportunistic: child health is known to be influenced by many factors, relatively good data is available, and the research on the topic is abundant and with fairly clear conclusions. Additionally, the focus on child health allows us to tackle several of the targets proposed in the MDGs at once (i.e., for malnutrition and infant/child mortality) and to emphasize the links between these various targets.

A number of studies have looked at the determinants of child (and maternal) health using cross-country data. These studies typically find a large impact of income (or proxies for income), with elasticity estimates ranging from 0.5 to 0.8 , with the causality clearly running from wealthier to healthier (Pritchett and Summers, 1996). The relationship with inequality is less clear, however. Filmer and Pritchett (1999) find that both income and its distribution matter, while Anand and Ravallion (1993) and Waldmann (1992) conclude that inequality is most important. Finally, Easterly (1999) 
finds a positive and robust relationship between both income and growth and child mortality and nutritional status.

A few other key variables are typically found to be important determinants of child health and nutrition. Thus Filmer and Pritchett (1999) find that 95 percent of cross country variations in infant or child mortality can be explained by just 5 variables -- GDP per capita, income distribution, female illiteracy rates, ethnolinguistic fractionalization and the predominant religion of a country. They argue that cross country studies on the topic can be summarized as follows: a) socio-economic characteristics explain nearly all the variation in mortality rates across countries; and b) public expenditure on health has much less impact on average health status than expected or hoped for. The latter point is explored in Filmer, Hammer and Pritchett (1997) who emphasize the importance of understanding the health seeking behavior of individuals, as well as the incentives facing health care providers in order to design health programs that are efficient and effective.

Two recent studies based on aggregated household data from demographic and health surveys (DHS) provide additional cross country evidence. Rutstein (2000) finds the strongest determinants of child mortality to be, in decreasing order of importance, the percentage of births that are the mother's fourth or more, the percentage of children born to mothers younger than 18 , the percentage of children born to underweight mothers and the percentage of households with drinking water from a surface source. The regressions do not include income variables however. Wang (2002) who combines DHS and World Development Indicators data for a sample of 41 developing countries finds that the child mortality rate decreases with higher GDP per capita, higher rural share of the population, vaccination, and greater access to electricity. For infant mortality rates, public expenditure on health and access to improved sanitation were also found to be significant. The work of Wang suffers from several limitations however, including the small sample size and the absence of income or inequality variables.

There has also been increased interest in recent years on the impact of environmental health factors on child and maternal health. Thus, according to the WHO's 2002 World Health Report, unsafe water, poor sanitation and hygiene are the cause of 4 to 8 percent of the overall burden of diseases in developing countries and nine-tenths of diarrheal diseases. Given the importance of infrastructure - particularly water and 
sanitation, transport, and electricity -- to environmental health, we review the literature on this topic, which tends to rely more on household level data.

The clearest link to emerge from micro-household studies are those between water, sanitation and hygiene (WSH) and health. Esrey et al. (1991) reviewed 49 studies showing an average 22 percent reduction in diarrheal morbidity from improved water and sanitation. Some of the most convincing evidence comes from a natural experiment that occurred in Argentina as a result of privatization of about 30 percent of the country's municipal utilities, covering 60 percent of the country's population. This was studied by Galiani et al. (2002) who found, using the variation in ownership of water provision (and the associated increase in coverage and improvement in quality of water services), that child mortality fell 5 to 9 percent in areas that privatized their water services. The effect was largest in poorer areas. The authors check the robustness of these results in a number of ways and clearly establish that privatization is associated with significant reductions in death from infectious and parasitic diseases, but is uncorrelated with deaths from causes unrelated to water conditions.

In addition, in their exhaustive review of the links between infrastructure and poverty, Brenneman and Kerf (2002) also highlight some of the relationships identified in the literature between health and transport and electricity. They find evidence reported in various studies that better transport contributes to easier access to health care as well as easier staffing and operation of clinics. Moreover, improved transport policy can reduce emissions of carbon dioxide which affect acute respiratory infections (ARI) and lead pollution, both of which are particularly harmful to children.

As to electricity, it is a clean fuel that reduces indoor air pollution (although there are options other than electricity that offer healthier alternatives to traditional bio-mass) and allows for a reduction in household accidents such as paraffin poisoning and burns associated with other commonly used fuels. ${ }^{7}$ By reducing the cost of boiling water, access to electricity can also be shown to improve hygiene. Finally, availability of electricity is essential to the provision of health care and the functioning of clinics. ${ }^{8}$

\footnotetext{
7 These are common, and sometimes fatal, accidents for children of poor households in developing countries.

${ }^{8}$ In particular, vaccines require continuous and reliable refrigeration to retain their effectiveness. For a discussion of these issues and an in-depth review of the literature, see Brenneman and Kerf (2002.)
} 
Finally, basic services affect school attendance, as well as educational performance, which in turn may be linked with health outcomes. The literature quoted in Brenneman and Kerf (2002) shows that electricity allows for more studying, transport promotes easier establishment of schools and higher attendance because of reduced transit time and safer passage to schools, and access to piped water frees girls to go to school and contributes both to higher achievement and attendance by promoting better health.

\section{Modeling Child Health Outcomes Using Cross-Country Quintile Data}

In order to assess the determinants of child health, we use a database constructed by Gwatkin et al. (2000) from Demographic and Health Survey (DHS) conducted in 43 developing countries ${ }^{9}$. The data are broken down by asset quintiles based on a principal component analysis of various asset variables available in the surveys. The use of asset quintiles follows from the fact that DHS data do not include income or consumption. ${ }^{10}$ The advantage of using these data is that we are able to go beyond traditional crosscountry regressions by exploiting some of the variability in outcomes and explanatory variables observed within country. In addition, using quintile level data substantially increases the sample size for the regressions.

Our measures of child health outcomes are the rate of infant mortality, the rate of child mortality, and the rate of malnutrition. These three outcomes are assumed to be determined by three broad categories of variables: the prevalence of diseases in the community, the general health condition of a child, and whether the child is medically treated when ill. Our objective is to estimate a reduced form model of the determinants of these various aspects of a child's health as a function of key policy variables.

Since disease prevalence is affected by the availability and quality of infrastructure such as water and sanitation, electricity, and the quality of the dwelling (particularly whether the floor is dirt or a finished surface), we include such variables as explanatory factors. Specifically, the household infrastructure variables are the shares of household within each asset quintile with a sand or pounded earth floor, with access to

\footnotetext{
${ }^{9}$ The list of countries is given in appendix. For information on DHS see http://www.measuredhs.com/

${ }^{10}$ Filmer and Pritchett (1998) show convincingly that that an asset index, calculated as it is here, using principal component techniques, is an excellent proxy for household income.
} 
piped water; without improved sanitation, and with access to electricity (a proxy for reduced indoor air pollution, although there are clearly alternatives to traditional, polluting practices other than electricity. ${ }^{11}$ )

The impact of environmental health factors on the prevalence of diseases is also likely to be itself affected among others by the characteristics of the members of the household such as the level of education of the mother which matters for fertility and hygiene practices. Although DHS surveys do generally have information on mothers' education, our database by asset quintiles does not. We therefore use the national female literacy rate from the World Development Indicators as a proxy.

As to the general health condition of a child, it is largely determined by the child's nutritional status - malnutrition puts children at risk of mortality from diarrhea, malaria, measles and pneumonia among others (WHO, 2002) -- and the degree to which he/she has benefited from medical attention before birth or soon thereafter. Thus, we use as explanatory variables the share of children who are malnourished, the share of children with full vaccination, the share of pregnancies for which there was antenatal care, the share of births attended medically, and the share of mothers with low body mass index.

As to the availability of treatment when a child is ill, we use information on treatment for the two types of diseases that are most prevalent in developing countries, namely, the share of children attended by a health professional (including pharmacist) when suffering from acute respiratory infection (ARI) and diarrhea.

Apart from including information according to the household asset quintile to which a child belongs, we add a number of country-level variables as controls. Following Filmer and Pritchett (1999), we include national GDP per capita, a measure of ethno-linguistic fractionalization, a measure of income inequality (the Gini coefficient), and the urbanization rate since in developing countries health care tends to be much less easily accessible in rural areas than in cities (Jayasuriya and Wodon, 2003). These variables are from the World Development Indicators complemented by data from Milanovic (2002) for countries with missing Ginis, except for ethno-linguistic fractionalization which is from Easterly and Levine (1996).

${ }^{11}$ For the Dominican Republic and Turkey, we relied on ownership of a television as a proxy. 
Given that we use data from 43 countries, with five asset quintiles by country, we have a theoretical maximum of 215 observation. In practice, we have only 175 observations because of missing dependant variables. ${ }^{12}$ We experimented with linear, semi- $\log$ and $\log$ forms. The linear and semi-log forms yielded similar results (as measured by the $\mathrm{R}^{2}$ and statistically significant variables) to those presented here. We settled on the $\log$ forms for ease of interpretation (i.e., to interpret coefficients as elasticities). The regressions were estimated as Seemingly Unrelated Regressions using the Stata package.

\section{Empirical Results}

\subsection{Baseline Results}

Table 1 provides the baseline results from the estimation. Regressions 1-3 suggest that after controlling for other variables, national-level GDP per capita remains a strong determinant of health outcomes. The elasticity is largest for malnutrition, with a 10 percent increase in GDP per capita leading to a 2.5 percent reduction in the prevalence of malnutrition. National-level female illiteracy is also statistically significant for all three outcomes, with an estimated elasticity of 0.4 in each case. Thus, a 10 percent reduction in female illiteracy improves the health outcomes by 4 percent. National-level income inequality and fractionalization are statistically significant only for child mortality, while urbanization is statistically significant only for child malnutrition.

We now turn to variables at the quintile level. The asset quintile dummies are always statistically significant. For example, the estimates imply that infant mortality is 41 percent higher in the poorest asset quintile than in the richest (note that this variable is in semi-log form, while all other variables are in log form). Higher child malnutrition leads to higher infant and child mortality, with an elasticity varying between 0.21 and 0.30. Note that excluding the malnutrition variable from regressions 1-2 generated higher coefficients for GDP in those regressions, suggesting that part of the income effect on health outcomes works through the reduction in malnutrition documented in regression 3. The coefficient on the mother's Body Mass Index (BMI) is strongly significant for child

\footnotetext{
${ }^{12}$ Note that when explanatory variables are missing, the variable is set to zero and a dummy variable equal to 1 is included in that regression.
} 
malnutrition and marginally significant but with the "wrong" sign for infant and child mortality. One possible interpretation is that once we correct for the child's nutritional status, a low mother BMI may in some cases signal a sedentary life or upper class status.

None of the medical attention variables seem to affect infant and child mortality. Vaccination and antenatal care also do not seem to improve malnutrition. When children get medical attention when ill with diarrhea or with acute respiratory infection, the rate of malnutrition is actually higher, not lower. Our interpretation is that medical attendance as measured here may be a proxy for a child getting seriously ill rather than for a child receiving appropriate care. Also, causality may run in both directions, since illnesses, and particularly diarrhea diseases, do contribute to low nutritional status.

\subsection{The relevance of infrastructure}

Looking at the infrastructure variables, we find that access to water reduces child and infant mortality. While the elasticity may seem low, the effect is in fact quantitatively large, explaining about a quarter of the difference in infant mortality between the poorest and richest quintiles and 37 percent of the difference in child mortality. In other words, increasing the poorest quintile's access to piped water from its dismally low 3 percent level to the level of the richest quintile at 55 percent would eliminate more than a quarter of the difference in infant mortality between these two groups, and more than a third of the difference in child mortality. The lack of improved sanitation and improved flooring are also statistically significant determinants of malnutrition. The difference in access to sanitation and good flooring between quintiles one and five accounts for 20 percent and 10 percent, respectively, of the difference between rich and poor in the prevalence of malnutrition. Access to electricity, by contrast, is never statistically significant.

Since infrastructure variables are strongly correlated with one another, and since the environmental health impact of access to infrastructure is likely due to a combination of clean water, lack of indoor pollution, good sanitation and decent dwelling quality, we replaced in regressions 4-6 the variables with an infrastructure index representing a principal component index for these variables. This infrastructure index has a strong and significant impact on mortality with a 10 percent increase in the index resulting in a 1.2 
to 1.9 percent reduction in mortality. Other coefficients remain broadly unchanged by the use of the infrastructure index instead of the original infrastructure variables.

\subsection{Including disease prevalence as an independent variable}

The previous results are generally fairly intuitive and "well-behaved" although they leave us with the rather unsatisfactory result that none of the medical intervention variables used here seem to matter. One explanation could be that we are using the wrong variables. Another could be that the relationship is more complex than portrayed here. In fact, it is very possible that these interventions affect disease prevalence, but that the impact of disease prevalence on mortality depends on whether the child is otherwise strong, whether the mother's education allows her to care for her child well, etc.

To test this hypothesis we include diarrhea prevalence as an explanatory variable in the regressions, while looking at the same time at the determinants of the prevalence of this disease. The results are presented in Table 3, regressions $7-10^{13}$. The elasticities with respect to diarrhea prevalence of infant and child mortality, as well as that of malnutrition, are found to be statistically significant (with values of $0.17,0.27$, and 0.5 respectively). Also, once we include diarrhea prevalence as an explanatory variable, the estimates of the coefficients for GDP per capita and the asset quintiles dummies decrease (particularly in the malnutrition regression), suggesting again than the effects of income and wealth on child health outcomes work in part through their impact on the prevalence of key diseases. Note also that national-level income inequality as measured by the Gini index is no longer a significant determinant of child mortality.

Looking at medical intervention variables, we still find that none of them appears to have any direct impact on infant and child mortality. However, a 10 percent increase in vaccination is now associated with a 1.7 percent reduction in the prevalence of diarrhea, and medical delivery attendance appears to reduce the prevalence of malnutrition. As to whether a child is seen medically when ill with diarrhea, it is again

\footnotetext{
${ }^{13}$ We also ran a model adding another equation with ARI prevalence as a dependent variable and as an explanatory variable for infant and child mortality and for malnutrition. While the ARI regression was fairly well behaved, ARI prevalence had a positive impact on child mortality-in other words, quintiles with higher ARI prevalence tend to have lower mortality, all else equal. Part of the explanation may be that ARI prevalence is capturing the high pollution level of the middle income countries that constitute the richer part of our sample. ARI, at least in our sample, appears to be a disease of poor people in rich countries, being positively correlated with GDP per capita and negatively with household wealth quintiles.
} 
positively associated with malnutrition (the interpretation could again be that quintiles with high medical attendance for ARI or diarrhea are those were children are sickest and most malnourished.)

For the infrastructure variables, we would expect to find an impact on diarrhea prevalence, given the WHO's result that 88 percent of diarrheal diseases are due to unsafe water, sanitation and hygiene (WHO 2002.) We find that electricity and a lack of sanitation are indeed important of determinants of the prevalence of diarrhea. For electricity, this supports results found elsewhere that households with electricity are more likely to boil water and properly cook food (see the review in Brenneman and Kerf, 2002.) For sanitation, the result explains a large share of the cross-quintile differences in diarrhea despite the small elasticity. Finally, we still find that water has a significant impact on both child and infant mortality.

\subsection{Interaction terms}

As mentioned in the introduction, the impact of infrastructure is likely to be higher if combined with health and education interventions. This can be tested using our model by introducing interaction terms between variables for infrastructure, health or education. To make this more wieldy, we use principal component indices for the health and infrastructure variables. For education, we continue to rely on the national-level literacy rate, but we transform the illiteracy rate (a "bad") into a literacy rate (a "good") so as to have all three variables for health, education, and infrastructure coded in a similar way (i.e., so that "more" is better).

As shown in Table 4, for infant mortality the results don't suggest that there is much additional explanatory power to be picked up from the interaction terms. For child mortality, the impact of infrastructure increases with education, and vice-versa, since the coefficient of the interaction term is positive and statistically significant. The coefficient on the infrastructure principal component index, however, is no longer statistically significant suggesting that for low levels of education, the impact of infrastructure on child mortality is vanishing. By contrast education continues to reduce infant and child mortality even if infrastructure endowments are low. For malnutrition, both health and education interventions appear to condition the impact of infrastructure. Note however 
that the coefficient of the infrastructure variable now has the wrong sign, which may suggest that the effect of infrastructure on malnutrition could be largely through its interaction with health and education interventions.

\section{Conclusion}

The importance of adequate, affordable, and universal or at least widely accessible health care is recognized as essential to improving child health outcomes. It is also well understood that mothers' education is a key determinant of the well being of children - whether by reducing fertility or by facilitating the adoption of good nutritional and hygienic practices. What we have argued, however, is that achieving the health and education MDGs will require more than health and education interventions. In particular, infrastructure services have an important role to play, and a failure to recognize this in planning MDG strategies will risk undermining success. After a quick review of the literature as it pertains to the achievement of the child health MDGs, we have outlined and estimated a simple reduced form model for analyzing the determinants of child health outcomes using cross-country quintile-level data. The use of such data has enabled us to go beyond traditional cross-country regressions by exploiting some of the variability in outcomes and explanatory variables observed between asset quintiles within countries.

We find that at the national level, GDP per capita, female illiteracy and ethnolinguistic fractionalization all affect infant and child mortality. At the quintile level, the households' asset levels (which is used to define the quintiles), the prevalence of diseases (as proxied by the rates of malnutrition and diarrhea), and the level of access to piped water also affect infant and child mortality. By contrast, the various direct measures of health interventions do not provide much explanatory power. This could be due either to the fact that we do not use the right measures of access to quality health care, or that measurement of the health care effect is made difficult by the presence of reverse causation - a child being treated could either mean that he/she has access to health care, or that he/she is severely ill possibly because of general weakness. It may also be that medical treatment has a larger impact on disease prevalence than on mortality, so that once we control for disease prevalence, we do not find large impacts. 
Concerning the prevalence of malnutrition, it is associated with national GDP per capita and female illiteracy, and at the quintile level with diarrhea prevalence (note that causality may run both ways as weaker children are more at risk of catching diarrheal diseases), the mother's nutritional status, delivery attendance at birth, the absence of sanitation and the presence of a dirt floor in the house. The relationship between low mother body mass index and child malnutrition may capture the fact that malnourished mothers have low birth weight babies, but also the fact that both mother and child are suffering from the same lack of income to purchase food. Key determinants for the prevalence of diarrhea across countries and asset quintile groups appear to be the national levels of GDP, income inequality, and female illiteracy, plus, at the quintile level, the vaccination rate, the mother's nutritional status, access to sanitation, access to electricity, as well as the asset quintiles themselves.

One important finding is that GDP per capita becomes less important once a more complete set of explanatory variables (including disease prevalence) is used for analyzing the determinants of health outcomes. Instead, variables which are perhaps easier to affect than GDP per capita are found to be key - most important are certainly female literacy and interventions that reduce the prevalence of diarrheal diseases and malnutrition. This in turn includes a number of health and infrastructure interventions.

Concerning the impact of infrastructure variables, particularly water and sanitation, the news is both interesting and challenging. It is interesting in the sense that we find that the we can explain a substantial portion of the difference in health outcomes between rich and poor through the difference in service coverage. This is good news because presumably it is easier to aim for universal access to water, sanitation, and electricity than for universal wealth. But it poses a daunting development challenge in the sense that the efforts required are still huge - significantly improving child health outcomes will require enormous increases in water and sanitation coverage of the poorer populations.

Finally, another important finding concerns the interaction effects between education, health, and infrastructure variables for improving child health outcomes. For both child mortality and malnutrition, the impact of infrastructure seems to be conditioned by the level of education and the use of adequate health services. In other 
words, achieving the child health goals put forward in the MDGs will probably require combined interventions on many different fronts to build upon cross-sectoral synergies. 


\section{References}

Adelman, Irma and Sherman. Robinson. Income Distribution Policy in Developing Countries: a Case Study of Korea, Oxford university Press, 1975.

Adelman, Irma.. "Development Economics-A Reassessment of Goals" American Economic Review 65 (1975) no.2, pp 302-309.

Brenneman, Adam and Michel Kerf. 2002. "Infrastructure \& Poverty Linkages, A Literature Review.” The World Bank, Washington, D.C. Processed.

Burki, S.J. and J.J.C. Voorhoeve. 1977. Global Estimates for Meeting Basic Needs. World Bank, D.C.

Crosswell, Michael. 1981. "Growth, Poverty Alleviation and Foreign Assistance" in Leipziger (1981.)

Chong, Alberto and Jesko Hentschel. 2003. "Bundling of Basic Services and Household Welfare in Developing Countries: The Case of Perú." World Bank, Washington, D.C. Processed.

De Melo, Martha, 1981. "Modifying the Effects of Alternative Approaches to Basic Human Needs: A Case Study of Linkages," in Leipziger (1981.)

Dervis, Kemal, J. de Melo, and S. Robinson. 1982. General Equilibrium Models for Development Policy. Cambridge University Press.

Easterly, William. 1999 "Life during growth." Policy Research Working Paper No. 2110. World Bank, Washington DC. Processed.

Easterly, William and Ross Levine. 1997. “Africa's growth Tragedy.” Quarterly Journal of Economics, 112:1203-50.

Filmer, Deon, Jeffrey Hammer and Lant Pritchett. October 22, 1997, "Health policy in poor countries: Weak Links in the Chain." Policy Research Working Paper No. 1874. World Bank, Washington, D.C. Processed.

Filmer, Deon and Lant Prichett. 1998. "Estimating Wealth Effects without expenditure data or tears." Policy Research Working Paper No. 1994. World Bank, Washington, D.C. Processed.

Filmer, Deon and Lant Prichett. 1999. "The impact of public spending on Health: does money matter?" Social Science and Medicine, 49: 1309-1323.

Gwatkin, Davidson R., Shea Reutstein, Kiersten Johnson, Rphini P. Pande, and Adam Wagstaff. 2000. "Socio-Economic Differences in Health, Nutrition, and 
Population.” World Bank, HNP/Poverty Thematic Group, Washington, D.C. Processed.

Galiani, Sebastian, Paul Gertler, and Ernesto Schargrodsky. 2002, "Water for life: The impact of the privatization of water services on child mortality." Universidad de San Andres, Argentina. Processed.

Hicks, Norman and P. Streeten. 1978. Indicators for Development: The Search for a Basic Needs Yardstick. World Bank, Washington, D.C.

Hicks, Norman. 1979. "Growth Versus Basic Needs: Is There a Tradeoff?" World Development, Vol. 7, no10/11, Nov/Dec.

Hicks, Norman, and Quentin Wodon. 2002. "Reaching the Millenium Development Goals in Latin America: Preliminary Results", En Breve No. 8, Latin America and Caribbean Region Vice Presidency, World Bank, Washington, DC. Available at http://www.worldbank.org/en breve

Jalan, Jyotsna and Martin Ravallion. 2001. "Does piped water reduce diarrhea for children in Rural India." Policy Research Working Paper No. 2664. World Bank, Washington, D.C. Processed.

Jayasuriya, Ruwan, and Quentin Wodon. 2003. "Efficiency in Reaching the Millenium Development Goals." World Bank Working Paper No. 9, Washington, DC. Processed.

Leipziger, Danny M. (ed.) 1981. Basic needs and Development. Oelgeschlager, Gunn and Ham, Cambridge.

Leipziger, Danny M. 1981. "Policy Issues and The Basic Human Needs Approach," in Leipziger (1981.)

Lewis, Maureen. 1981. "Sectoral Aspects of a Basic Human Needs Approach: The Linkages Among Population, Nutrition and Health," in Leipziger (1981.)

Milanovic, Branko. 1999. "True World Income Distribution, 1988 and 1993: First Calculations, Based on Household Surveys Alone". Policy Research Working Paper No. 2244. The World Bank, Washington DC. Processed.

Pritchett, Lant and Lawrence H. Summers. 1996 "Wealthier is healthier." The Journal of Human Resources, XXXI 4, pp 841-868.

Rutstein, Shea O. 2000, "Factors associated with trends in infant and child mortality in developing countries during the 1990s." World Health Organization. Geneva. Processed. 
Streeten, Paul, 1977, The Distinctive Features of The Basic Needs Approach to Development, World Bank, Washington, D.C.

Waldmann, Robert J. 1992. "Income distribution and infant mortality." The Quarterly Journal of Economics, 107, pp 1283-1302.

Wang, Limin. 2002, "Determinants of child mortality in LDCs: Empirical findings from demographic and health surveys." World Bank, Washington, D.C. Processed.

WHO (World Health Organization.) 2002. The World Health Report 2002, Reducing risks, promoting healthy life. Geneva. http://www.who.int/pub/en/ 
Figure 1. Infant Mortality and Child Malnutrition by Income Group
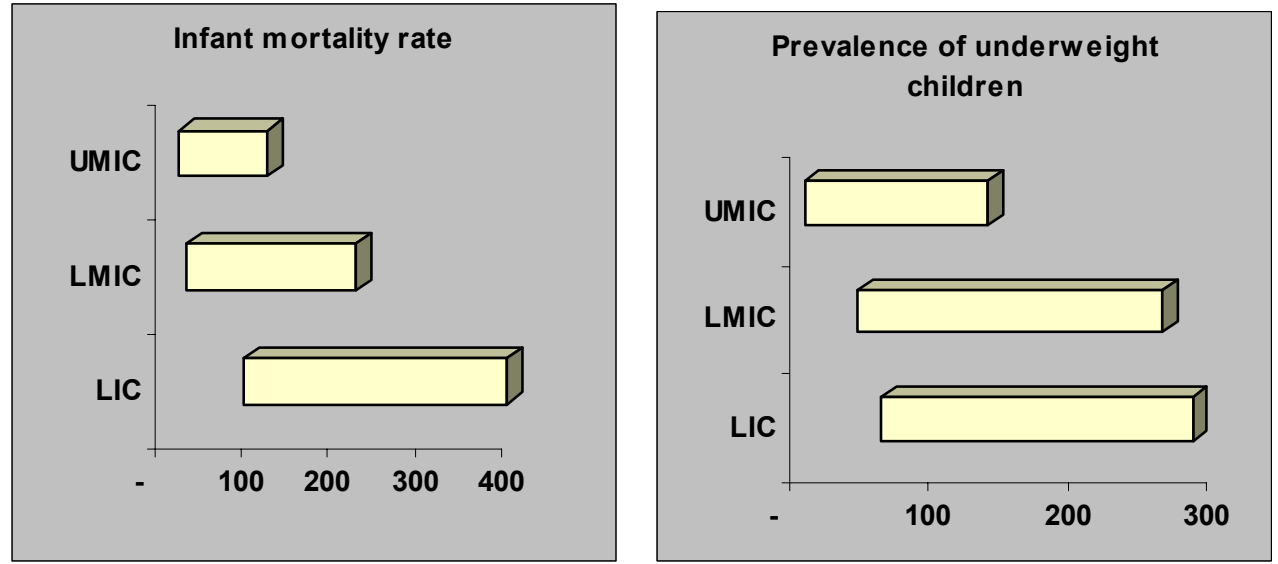

Source: Authors' calculations from World Development Indicators.

Note: Rates are normalized such that the sample average is set at 100. LIC, LMIC and UMIC are respectively low income countries (27 countries), lower middle income countries (19 countries) and upper middle income countries ( 28 countries) for a total sample of 74 developing countries.

Figure 2. Infrastructure, Health Care and Infant Mortality: Stylized Relationships

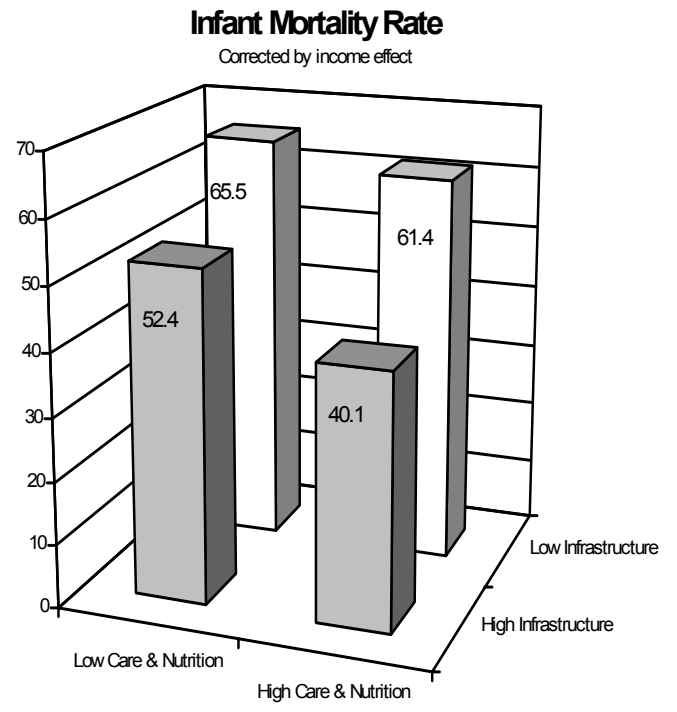

Source: Authors' calculations from World Development Indicators.

Note: The Figure is based on the following OLS regression: IMR $=8.43-0.51 Y-0.10$ Health +0.37 Infra, $\mathrm{R}^{2}=0.77$, where $\mathrm{Y}$ is GDP per capita, "Health" is a principal component index of birth attended by a health professional, measles vaccination and antenatal care, and "Infra" is a principal component index of household access to electricity, telephone, water and sanitation, and paved roads per capita. The regression was estimated on a sample of 56 developing country observations. We then looked at the part of IMRi that was not explained by income by fitting the following values: $I M R i^{*}=I M R i-0.51 \mathrm{Yi}$. The sample median values for health and infrastructure interventions were used to generate the four cells of the graph, i.e. countries with higher or lower values than the median for both variables were classified as such. This Figure is provided for heuristic purposes only. A more detailed analysis of the determinants of infant and child mortality, as well as child malnutrition is provided in the empirical section of this paper. 
Table 1: Selected indicators for the Millennium Development Goals by income level

\begin{tabular}{|c|c|c|c|c|c|c|}
\hline $\begin{array}{l}\text { Income group } \\
\text { (number of } \\
\text { countries per } \\
\text { group in } \\
\text { parenthesis) }\end{array}$ & $\begin{array}{c}\text { GDP per } \\
\text { capita, PPP } \\
\text { (\$US current } \\
\text { international) }\end{array}$ & $\begin{array}{l}\text { Proportion of } \\
\text { malnourished } \\
\text { children } / 1\end{array}$ & $\begin{array}{l}\text { Net primary } \\
\text { school } \\
\text { enrollment } \\
\text { (\% of relevant } \\
\text { age group) }\end{array}$ & $\begin{array}{l}\text { Ratio of young } \\
\text { literate females } \\
\text { to males } \\
\text { (ages } 15 \text { to } 24 \text { ) }\end{array}$ & $\begin{array}{c}\text { Child } \\
\text { Mortality } \\
\text { Rate } \\
\text { (per } 1000 \text { live } \\
\text { birth) }\end{array}$ & $\begin{array}{c}\text { Maternal } \\
\text { mortality } \\
\text { rate } \\
\text { (per } 100,000 \\
\text { live birth) }\end{array}$ \\
\hline Low (26) & 960 & 32 & 59 & 72 & 162 & 1,089 \\
\hline Medium (17) & 2,392 & 18 & 84 & 94 & 72 & 364 \\
\hline High $\quad(30)$ & 5,749 & 9 & 89 & 98 & 35 & 138 \\
\hline Average (73) & 3,261 & 19 & 77 & 88 & 89 & 529 \\
\hline
\end{tabular}

Source: Authors' calculations from World Development Indicators and UNICEF data.

Note: 1/ Malnutrition is the proportion of children under five falling below minus 2 standard deviations from the median weight-for-age of the reference population recognized by WHO. Income groups were calculated based on sample means: "high" are countries with income above the sample mean; a sub-sample mean was then calculated for remaining countries, which divides the sub-sample into "medium" and "low".

Table 2: Summary Statistics for the variables used in the empirical analysis

\begin{tabular}{|c|c|c|c|c|c|c|}
\hline & \multicolumn{5}{|c|}{ Asset quintiles } & \multirow[t]{2}{*}{$\begin{array}{l}\text { Sample } \\
\text { Average }\end{array}$} \\
\hline & 1 & 2 & 3 & 4 & 5 & \\
\hline Infant Mortality Rate (per thousand) & 90.7 & 87.0 & 80.3 & 70.7 & 51.4 & 76.0 \\
\hline Child Mortality Rate (per thousand) & 148.2 & 141.1 & 128.1 & 110.9 & 78.8 & 121.4 \\
\hline Malnutrition (\%) & 32.1 & 28.1 & 25.0 & 21.2 & 14.6 & 24.2 \\
\hline GDP per Capita (1995 US\$) & & & & & & 2220.3 \\
\hline Ethno-linguistic Fractionalization & & & & & & 0.6 \\
\hline Gini Index of Inequality & & & & & & 41.3 \\
\hline Urbanization Rate (\%) & & & & & & 30.3 \\
\hline Female Illiteracy (\%) & & & & & & 45.0 \\
\hline Antenatal Care (\%) & 56.8 & 66.8 & 72.8 & 82.1 & 91.9 & 74.1 \\
\hline Delivery Attendance at Birth (\%) & 31.4 & 42.5 & 51.7 & 66.3 & 83.9 & 55.2 \\
\hline Low mother BMI (\%) & 11.2 & 10.0 & 9.3 & 8.7 & 6.1 & 9.0 \\
\hline Vaccination $(\%)$ & 37.0 & 44.3 & 48.4 & 54.8 & 63.9 & 49.7 \\
\hline Medical Attendance for ARI (\%) & 29.8 & 36.4 & 40.4 & 44.2 & 53.9 & 40.9 \\
\hline Medical Attendance for diarrhea (\%) & 31.9 & 33.4 & 34.2 & 39.2 & 42.2 & 36.2 \\
\hline Dirt floor in dwelling (\%) & 71.1 & 60.1 & 41.8 & 26.0 & 8.9 & 41.6 \\
\hline Access to piped water (\%) & 3.1 & 9.3 & 16.8 & 30.3 & 55.1 & 22.9 \\
\hline Access to electricity (\%) & 14.0 & 26.3 & 36.3 & 52.8 & 80.2 & 41.9 \\
\hline No improved sanitation (\%) & 62.9 & 46.6 & 32.4 & 19.5 & 9.3 & 34.1 \\
\hline
\end{tabular}

Source: Authors' calculations from the data gathered by Gwatkin et al. (2000), on the basis of DHS data. 
Table 3: Determinants of child health outcomes, DHS data

\begin{tabular}{|c|c|c|c|c|c|c|}
\hline \multirow[b]{2}{*}{ Dependent variable } & 1 & 2 & 3 & 4 & 5 & 6 \\
\hline & $\begin{array}{c}\text { Infant } \\
\text { mortality }\end{array}$ & $\begin{array}{c}\text { Child } \\
\text { mortality }\end{array}$ & $\begin{array}{c}\text { Child } \\
\text { malnutrition }\end{array}$ & $\begin{array}{c}\text { Infant } \\
\text { mortality }\end{array}$ & $\begin{array}{c}\text { Child } \\
\text { mortality }\end{array}$ & $\begin{array}{c}\text { Child } \\
\text { malnutrition }\end{array}$ \\
\hline \multirow[t]{2}{*}{ GDP per capita } & -0.12 & -0.14 & -0.25 & -0.12 & -0.14 & -0.26 \\
\hline & $(3.01)^{* * *}$ & $(2.99)^{* * *}$ & $(4.33)^{* * *}$ & $(2.94)^{* * *}$ & $(3.05)^{* * *}$ & $(4.30)^{* * *}$ \\
\hline \multirow[t]{2}{*}{ Ethno-ling. Fractionalization } & 0.05 & 0.23 & -0.01 & 0.05 & 0.25 & 0.06 \\
\hline & $(0.63)$ & $(2.52)^{* *}$ & $(0.11)$ & $(0.63)$ & $(2.60)^{* * *}$ & $(0.48)$ \\
\hline \multirow[t]{2}{*}{ Gini index of inequality } & 0.12 & 0.29 & 0.02 & 0.07 & 0.23 & 0.10 \\
\hline & $(1.06)$ & $(2.40)^{* *}$ & $(0.14)$ & $(0.63)$ & $(1.87)^{*}$ & $(0.58)$ \\
\hline \multirow[t]{2}{*}{ Urbanization rate } & 0.01 & 0.00 & -0.04 & 0.01 & 0.00 & -0.03 \\
\hline & $(0.40)$ & $(0.08)$ & $(2.23)^{* *}$ & $(0.55)$ & $(0.17)$ & $(1.62)$ \\
\hline \multirow[t]{2}{*}{ Female illiteracy rate } & 0.39 & 0.38 & 0.41 & 0.40 & 0.41 & 0.41 \\
\hline & $(6.92)^{* * *}$ & $(5.95)^{* * *}$ & $(5.20)^{* * *}$ & $(7.13)^{* * *}$ & $(6.20)^{* * *}$ & $(5.01)^{* * *}$ \\
\hline \multirow[t]{2}{*}{ Underweight } & 0.21 & 0.30 & & 0.20 & 0.28 & \\
\hline & $(4.08)^{* * *}$ & $(5.18)^{* * *}$ & & $(4.15)^{* * *}$ & $(5.04)^{* * *}$ & \\
\hline \multirow[t]{2}{*}{ Vaccination } & -0.04 & -0.08 & -0.02 & -0.04 & -0.08 & 0.00 \\
\hline & $(0.84)$ & $(1.63)$ & $(0.22)$ & $(0.88)$ & $(1.66)^{*}$ & $(0.05)$ \\
\hline \multirow[t]{2}{*}{ Antenatal care } & -0.06 & 0.02 & 0.04 & -0.06 & 0.06 & -0.01 \\
\hline & $(0.66)$ & $(0.21)$ & $(0.34)$ & $(0.69)$ & $(0.65)$ & $(0.07)$ \\
\hline \multirow[t]{2}{*}{ Deliv. attendance at birth } & 0.09 & 0.11 & -0.18 & 0.11 & 0.12 & -0.17 \\
\hline & $(1.41)$ & $(1.60)$ & $(1.97)^{* *}$ & $(1.80)^{*}$ & $(1.73)^{*}$ & $(1.85)^{*}$ \\
\hline \multirow[t]{2}{*}{ Low mother BMI } & -0.08 & -0.09 & 0.34 & -0.06 & -0.05 & 0.33 \\
\hline & $(1.84)^{*}$ & $(1.75)^{*}$ & $(5.59)^{* * *}$ & $(1.48)$ & $(0.96)$ & $(5.35)^{* * *}$ \\
\hline \multirow[t]{2}{*}{ Med. Attendance for ARI } & 0.02 & -0.09 & 0.17 & 0.02 & -0.10 & 0.22 \\
\hline & $(0.32)$ & $(1.37)$ & $(2.04)^{* *}$ & $(0.41)$ & $(1.52)$ & $(2.67)^{* * *}$ \\
\hline \multirow[t]{2}{*}{ Med. Attend. for diarrhea } & 0.01 & -0.02 & 0.12 & 0.01 & -0.01 & 0.06 \\
\hline & $(0.13)$ & $(0.50)$ & $(1.93)^{*}$ & $(0.13)$ & $(0.24)$ & $(0.90)$ \\
\hline \multirow[t]{2}{*}{ Dirt floor in dwelling } & 0.01 & 0.01 & 0.04 & & & \\
\hline & $(0.61)$ & $(0.54)$ & $(1.88)^{*}$ & & & \\
\hline \multirow[t]{2}{*}{ Access to piped water } & -0.05 & -0.08 & 0.03 & & & \\
\hline & $(2.24)^{* *}$ & $(3.21)^{* * *}$ & $(0.90)$ & & & \\
\hline \multirow[t]{2}{*}{ Access to electricity } & 0.01 & 0.00 & 0.01 & & & \\
\hline & $(0.66)$ & $(0.08)$ & $(0.43)$ & & & \\
\hline \multirow[t]{2}{*}{ No improved sanitation } & 0.00 & -0.01 & 0.08 & & & \\
\hline & $(0.29)$ & $(0.51)$ & $(4.01)^{* * *}$ & & & \\
\hline \multirow[t]{2}{*}{ Infrastructure PC index } & & & & -0.12 & -0.19 & -0.07 \\
\hline & & & & $(1.99)^{* *}$ & $(2.86)^{* * *}$ & $(0.74)$ \\
\hline \multirow[t]{2}{*}{ Asset quintile 1} & 0.41 & 0.25 & 0.54 & 0.42 & 0.33 & 0.67 \\
\hline & $(4.31)^{* * *}$ & $(2.32)^{* *}$ & $(4.02)^{* * *}$ & $(4.67)^{* * *}$ & $(3.13)^{* * *}$ & $(5.04)^{* * *}$ \\
\hline \multirow[t]{2}{*}{ Asset quintile 2} & 0.39 & 0.25 & 0.42 & 0.41 & 0.34 & 0.54 \\
\hline & $(4.79)^{* * *}$ & $(2.78)^{* * *}$ & $(3.60)^{* * *}$ & $(5.50)^{* * *}$ & $(3.92)^{* * *}$ & $(4.91)^{* * *}$ \\
\hline \multirow[t]{2}{*}{ Asset quintile 3} & 0.32 & 0.20 & 0.32 & 0.35 & 0.28 & 0.40 \\
\hline & $(4.61)^{* * *}$ & $(2.49)^{* *}$ & $(3.11)^{* * *}$ & $(5.53)^{* * *}$ & $(3.84)^{* * *}$ & $(4.25)^{* * *}$ \\
\hline \multirow[t]{2}{*}{ Asset quintile 4} & 0.25 & 0.16 & 0.19 & 0.27 & 0.21 & 0.25 \\
\hline & $(4.45)^{* * *}$ & $(2.52)^{* *}$ & $(2.24)^{* *}$ & $(4.98)^{* * *}$ & $(3.36)^{* * *}$ & $(3.01)^{* * *}$ \\
\hline $\mathrm{R}^{2}$ & 0.81 & 0.85 & 0.85 & 0.80 & 0.84 & 0.83 \\
\hline Number of Observations & 175 & 175 & 175 & 175 & 175 & 175 \\
\hline
\end{tabular}


Table 4: Determinants of child health outcomes, including disease prevalence, DHS data

\begin{tabular}{|c|c|c|c|c|}
\hline & 7 & 8 & 9 & 10 \\
\hline Dependent variable & $\begin{array}{c}\text { Infant } \\
\text { mortality }\end{array}$ & $\begin{array}{c}\text { Child } \\
\text { mortality }\end{array}$ & $\begin{array}{l}\text { Child } \\
\text { malnutrition }\end{array}$ & $\begin{array}{c}\text { Diarrhea } \\
\text { prevalence }\end{array}$ \\
\hline \multirow[t]{2}{*}{ GDP per capita } & -0.109 & -0.115 & -0.184 & -0.117 \\
\hline & $(2.66)^{* * *}$ & $(2.53)^{* *}$ & $(3.24)^{* * *}$ & $(2.61)^{* * *}$ \\
\hline \multirow[t]{2}{*}{ Ethno-linguistic fractionalization } & 0.063 & 0.252 & 0.017 & -0.099 \\
\hline & $(0.78)$ & $(2.80)^{* * *}$ & $(0.15)$ & $(1.02)$ \\
\hline \multirow[t]{2}{*}{ Gini index of inequality } & 0.051 & 0.191 & -0.152 & 0.272 \\
\hline & $(0.46)$ & $(1.56)$ & $(0.97)$ & $(2.23)^{* *}$ \\
\hline \multirow[t]{2}{*}{ Urbanization rate } & 0.005 & -0.002 & -0.04 & -0.005 \\
\hline & $(0.37)$ & $(0.13)$ & $(2.16)^{* *}$ & $(0.35)$ \\
\hline \multirow[t]{2}{*}{ Female illiteracy rate } & 0.38 & 0.36 & 0.33 & 0.197 \\
\hline & $(6.79)^{* * *}$ & $(5.82)^{* * *}$ & $(4.35)^{* * *}$ & $(3.32)^{* * *}$ \\
\hline \multirow[t]{2}{*}{ Child Malnutrition } & 0.162 & 0.225 & & \\
\hline & $(3.06)^{* * *}$ & $(3.84)^{* * *}$ & & \\
\hline \multirow[t]{2}{*}{ Vaccination } & -0.02 & -0.053 & 0.034 & -0.166 \\
\hline & $(0.44)$ & $(1.08)$ & $(0.54)$ & $(3.46)^{* * *}$ \\
\hline \multirow[t]{2}{*}{ Antenatal care } & -0.08 & -0.021 & -0.031 & 0.11 \\
\hline & $(0.98)$ & $(0.23)$ & $(0.26)$ & $(1.17)$ \\
\hline \multirow[t]{2}{*}{ Diarrhea prevalence } & 0.168 & 0.269 & 0.449 & 0.168 \\
\hline & $(2.42)^{* *}$ & $(3.50)^{* * *}$ & $(4.82)^{* * *}$ & $(2.42)^{* *}$ \\
\hline \multirow[t]{2}{*}{ Delivery attendance at birth } & 0.066 & 0.079 & -0.208 & 0.082 \\
\hline & $(1.10)$ & $(1.18)$ & $(2.46)^{* *}$ & (1.19) \\
\hline \multirow[t]{2}{*}{ Low mother body mass index } & -0.046 & -0.031 & 0.394 & -0.11 \\
\hline & $(1.01)$ & $(0.62)$ & $(6.76)^{* * *}$ & $(2.29)^{* *}$ \\
\hline \multirow[t]{2}{*}{ Medical attendance for ARI } & 0.034 & -0.058 & 0.19 & \\
\hline & $(0.63)$ & $(0.97)$ & $(2.49)^{* *}$ & \\
\hline \multirow[t]{2}{*}{ Medical attendance for diarrhea } & 0.031 & 0.018 & 0.171 & \\
\hline & $(0.74)$ & $(0.38)$ & $(2.95)^{* * *}$ & \\
\hline \multirow[t]{2}{*}{ Dirt floor in dwelling } & 0.014 & 0.018 & 0.049 & -0.021 \\
\hline & $(1.06)$ & $(1.21)$ & $(2.61)^{* * *}$ & $(1.35)$ \\
\hline \multirow[t]{2}{*}{ Access to piped water } & -0.05 & -0.08 & 0.027 & 0.005 \\
\hline & $(2.27)^{* *}$ & $(3.32)^{* * *}$ & $(0.85)$ & $(0.18)$ \\
\hline \multirow[t]{2}{*}{ Access to electricity } & 0.023 & 0.012 & 0.036 & -0.043 \\
\hline & $(1.06)$ & $(0.50)$ & $(1.15)$ & $(1.70)^{*}$ \\
\hline \multirow[t]{2}{*}{ No improved sanitation } & -0.008 & -0.014 & 0.065 & 0.048 \\
\hline & $(0.52)$ & $(0.86)$ & $(3.25)^{* * *}$ & $(2.98) * * *$ \\
\hline \multirow[t]{2}{*}{ Asset quintile 1} & 0.383 & 0.209 & 0.417 & 0.289 \\
\hline & $(4.11)^{* * *}$ & $(2.03)^{* *}$ & $(3.23)^{* * *}$ & $(2.77)^{* * *}$ \\
\hline \multirow[t]{2}{*}{ Asset quintile 2} & 0.371 & 0.228 & 0.327 & 0.213 \\
\hline & $(4.64)^{* * *}$ & $(2.57)^{* *}$ & $(2.94)^{* * *}$ & $(2.33)^{* *}$ \\
\hline \multirow[t]{2}{*}{ Asset quintile 3} & 0.306 & 0.168 & 0.233 & 0.199 \\
\hline & $(4.41)^{* * *}$ & $(2.19)^{* *}$ & $(2.39)^{* *}$ & $(2.48)^{* *}$ \\
\hline \multirow[t]{2}{*}{ Asset quintile 4} & 0.227 & 0.122 & 0.1 & 0.198 \\
\hline & $(4.03)^{* * *}$ & $(1.95)^{*}$ & $(1.25)$ & $(3.03) * * *$ \\
\hline $\mathrm{R}^{2}$ & 0.82 & 0.86 & 0.87 & 0.53 \\
\hline Number of observations & 175 & 175 & 175 & 175 \\
\hline
\end{tabular}


Table 5: Determinants of child health outcomes, with interaction terms, DHS data

\begin{tabular}{lccc}
\hline & 7 & 8 & 9 \\
\cline { 2 - 4 } Dependent variable & $\mathrm{IMR}$ & $\mathrm{U} 5 \mathrm{MR}$ & UNDERW \\
\hline GDP per capita & -0.155 & -0.181 & -0.308 \\
& $(4.45)^{* * *}$ & $(4.47)^{* * *}$ & $(5.76)^{* * *}$ \\
Ethno-linguistic fractionalization & 0.034 & 0.227 & 0.458 \\
Gini index of inequality & $(0.45)$ & $(2.58)^{* * *}$ & $(3.77)^{* * *}$ \\
& 0.064 & 0.254 & -0.156 \\
Urbanization rate & $(0.68)$ & $(2.32)^{* *}$ & $(1.00)$ \\
& 0.002 & 0.006 & -0.011 \\
Female illiteracy rate & $(0.18)$ & $(0.45)$ & $(0.55)$ \\
& 0.19 & 0.217 & -0.049 \\
Malnutrition & $(4.68)^{* * *}$ & $(4.58)^{* * *}$ & $(0.73)$ \\
Low mother body mass index & 0.225 & 0.265 & \\
Infrastructure PC index & $(5.23)^{* * *}$ & $(5.30)^{* * *}$ & \\
Health PC index & -0.073 & -0.033 & 0.389 \\
Health PC index * Infrastructure PC index & $(2.04)^{* *}$ & $(0.80)$ & $(7.32)^{* * *}$ \\
Fenmale Literacy * Infrastructure PC index & 0.101 & 0.035 & 1.58 \\
Asset quintile 1 & $(0.54)$ & $(0.16)$ & $(5.47)^{* * *}$ \\
Asset quintile 2 & -0.024 & -0.058 & 0.038 \\
Asset quintile 3 & $(0.32)$ & $(0.67)$ & $(0.31)$ \\
Asset quintile 4 & 0.049 & 0.171 & -0.701 \\
\hline $\mathrm{R}^{2}$ & $(0.50)$ & $(1.49)$ & $(4.48)^{* * *}$ \\
Number of observations & -0.07 & -0.119 & -0.137 \\
SOun & $(1.60)$ & $(2.35)^{* *}$ & $(1.91)^{*}$ \\
& 0.335 & 0.35 & 0.398 \\
& $(3.88)^{* * *}$ & $(3.48)^{* * *}$ & $(2.82)^{* * *}$ \\
& 0.349 & 0.365 & 0.297 \\
& $(4.59)^{* * *}$ & $(4.13)^{* * *}$ & $(2.38)^{* *}$ \\
& 0.318 & 0.338 & 0.184 \\
& $(4.81)^{* * *}$ & $(4.39)^{* * *}$ & $(1.68)^{*}$ \\
& 0.254 & 0.259 & 0.08 \\
& $(4.60)^{* * *}$ & $(4.02)^{* * *}$ & $(0.87)$ \\
\hline & 0.81 & 0.84 & 0.81 \\
\hline & 195 & 195 & 195 \\
\hline
\end{tabular}

Source: Authors' estimation. Absolute value of $\mathrm{z}$ statistics in parenthesis. * significant at $10 \%$; ** significant at $5 \%$; *** significant at $1 \%$. All variables in log except the assets dummies. Constant term included but not shown here. 


\section{Appendix: Data Sources, Variable Definitions and Sample of Countries}

Most national-level data are from the World Bank's World Development Indicators (http://www.worldbank.org/data/), complemented in the case of the inequality measure with data from Milanovic (1999.) The index of ethno-linguistic fractionalization for 1960 measures the probability that two randomly selected people from a given country will not belong to the same ethno-linguistic group, as reported in Easterly and Levine (1997.) The quintile level data are from Gwatkin et al. (2000). The methodology used to develop the asset quintiles is discussed at http://www.worldbank.org/poverty/health/data/index.htm. For information on Demographic and Health Surveys, see http://www.measuredhs.com/.

List of variables and definitions:

GDP per capita: in 1995 US dollars, from the World Development Indicators (WDI).

Gini: Gini coefficient, mostly WDI, complemented with data from Milanovic (1999).

Urbanization rate: Share of the country's population living in urban areas (WDI).

Female Illiteracy rate: Share of females ages 15 and above who cannot, with understanding, read and write a short, simple statement on their everyday life (WDI.)

Infant Mortality Rate: Number of deaths to children under 12 months of age per 1,000 live births, based on births in the 10 years preceding the survey (DHS.)

Under-Five Mortality Rate: Number of deaths to children under five years of age per 1,000 live births. Figures are based on births in the 10 years preceding the survey (DHS.)

Malnutrition: Share of children whose weight measurement is more than two standard deviations below the median reference standard for their age as established by the World Health Organization, the U.S. Centers for Disease Control, and the U.S. National Center for Health Statistics. The figures in the tables are based on a sample of living children under three, four, or five years of age, depending on the country (DHS.)

Percent of Mothers with Low Body Mass Index (BMI): Share of women whose BMI is less than 18.5, where BMI - an indicator of adult nutritional status - is defined as weight in kilograms divided by the square of height in meters. In some countries BMI is presented for all sample women, while in other countries the figure is available only for mothers of children under five years old (DHS.)

Vaccination rate: Share of surviving children age 12-23 months who received all vaccinations, namely BCG, three doses of DPT and oral polio, and measles (DHS.)

Diarrhea Prevalence: Share of surviving children under three, four, or five years old (depending on the country) who had diarrhea in the two weeks preceding the survey based on mothers' reports concerning the presence of loose stools (DHS.)

Medical attendance: Share of children with diarrhea in the past two weeks who were taken to any medical facility for treatment, defined as a private doctor, mission/hospital clinic, other private hospital/clinic, pharmacy, or a public facility (DHS.) 
Acute Respiratory Infection (ARI) Prevalence: Share of surviving children under three, four, or five years old (depending upon the country) who had a cough accompanied by rapid breathing in the two weeks preceding the survey, as defined and reported by the mother (DHS.)

ARI Medical attendance: Share of children with a cough and rapid breathing in the preceding two weeks who were taken to any medical facility for treatment (DHS.)

Antenatal Care: Share of births in the five years before the survey for which a woman received at least one antenatal care consultation from a medically trained person, defined as a doctor, nurse or nurse-midwife; at least one antenatal care consultation from a doctor; at least one antenatal care consultation from a nurse or nurse-midwife; two or more antenatal care consultations from a medically trained person (DHS.)

Delivery Attendance: Share of births in the five years prior to the survey that were attended to by a medically trained person, defined as a doctor, nurse or nurse-midwife, a doctor, a nurse-midwife (DHS.)

Dirt floor in dwelling: Share of dwellings that have a sand or dirt floor (DHS.)

Access to piped water: Share of dwellings that have piped water in the residence (DHS.)

Access to electricity: Share of households with electricity in the house (DHS.)

No improved sanitation: Share of households without any kind of improved sanitation, with the definition varying across surveys but generally including unimproved latrines or use of field and bush (DHS.)

The 43 countries included in the sample are:

\begin{tabular}{lclclc}
\hline Country & $\underline{\text { Year }}$ & Country & $\underline{\text { Year }}$ & Country & $\underline{\text { Year }}$ \\
\hline Bangladesh & $1996 / 7$ & Haiti & $1994 / 5$ & Nigeria & 1990 \\
Benin & 1996 & India & $1992 / 3$ & Pakistan & $1990 / 1$ \\
Bolivia & 1998 & Indonesia & 1997 & Paraguay & 1990 \\
Brazil & 1996 & Kazakhstan & 1995 & Peru & 1996 \\
Burkina Faso & $1992 / 3$ & Kenya & 1998 & Senegal & 1997 \\
Cameroon & 1991 & Kyrgyz Rep. & 1997 & Tanzania & 1996 \\
Central African Rep. & $1994 / 5$ & Madagascar & 1997 & The Philippines & 1998 \\
Chad & $1996 / 7$ & Malawi & 1992 & Togo & 1998 \\
Colombia & 1995 & Mali & $1995 / 6$ & Turkey & 1993 \\
Comoros & 1996 & Morocco & 1993 & Uganda & 1995 \\
Côte d'Ivoire & 1994 & Mozambique & 1997 & Uzbekistan & 1996 \\
Dominican Republic & 1996 & Namibia & 1992 & Vietnam & 1997 \\
Ghana & 1993 & Nepal & 1996 & Zambia & 1996 \\
Guatemala & 1995 & Nicaragua & $1997 / 8$ & Zimbabwe & 1994 \\
& & Niger & 1998 & & \\
\hline
\end{tabular}

